\title{
Сравнение эффективности перспективных гетероструктурных умножительных диодов терагерцового диапазона частот
}

\author{
() Д.И. Дюков ${ }^{1}$, А.Г. Фефрелов ${ }^{1}$, А.В. Коротков ${ }^{1,3}$, Д.Г. Павельев ${ }^{3}$, В.А. Козлов ${ }^{2,3}$, \\ Е.С. Оболенская ${ }^{3}$, А.С. Иванов ${ }^{1,3}$, С.В. Оболенский ${ }^{3}$ \\ ${ }^{1}$ ОАО Научно-производственное предприятие „Салют“, \\ 603950 Нижний Новгород, Россия \\ ${ }^{2}$ Институт фризики микроструктур Российской академии наук, \\ 607680 Нижний Новгород, Россия \\ ${ }^{3}$ Нижегородский государственный университет им. Н.И. Лобачевского, \\ 603950 Нижний Новгород, Россия \\ E-mail: elizaveta.obolenskaya@gmail.com; obolensk@rf.unn.ru \\ Поступила в Редакцию 15 апреля 2020 г. \\ В окончательной редакции 21 апреля 2020 г. \\ Принята к публикации 21 апреля 2020 г.
}

Приводятся результаты теоретического и экспериментального сравнения эффективности преобразования сигналов диодами на основе сверхрешеток с малым числом периодов ( $N$-образная вольт-амперная характеристика) и перспективными умножительными гетеробарьерными диодами (варакторами) (вольт-фарадная характеристика параболического вида).

Ключевые слова: диоды на основе сверхрешеток, нелинейная вольт-амперная характеристика, варактор, вольт-фарадная характеристика параболического вида, умножители частоты сигналов.

DOI: $10.21883 /$ FTP.2020.10.49961.43

\section{1. Введение}

Известно [1-3], что диоды с нелинейными вольтамперными и вольт-фарадными характеристиками могут использоваться в умножителях частоты сигналов, а вид нелинейности характеристик определяет, насколько эффективным будет преобразование мощности сигнала во 2-ю, 3-ю гармоники и гармоники более высокой кратности. В статье [4] мы уже сравнивали эффективность преобразования сигналов диодами Шоттки и диодами на основе сверхрешеток (CP) GaAs/AlAs (рис. 1,a), имеющих нелинейные вольт-амперные характеристики $I(U)$ (рис. 2), и определили, что умножительный диод на основе сверхрешетки имеет преимущество при использовании гармоник выше 3-й в диапазоне частот умноженного сигнала 0.1-1 ТГц. Было получено, что гармоники диодов на основе СР спадают медленнее, чем диодов Шоттки. Экспериментальная выходная мощность сигнала на 3-й гармонике больше, чем на 5-й, в 4 раза, а на 5-й гармонике больше в 3.5 раза, чем на 7-й [4].

В данной работе приводятся результаты теоретического и экспериментального сравнения эффективности преобразования сигналов диодами на основе сверхрешеток GaAs/AlAs [5,6] улучшенной конструкции (с меньшим числом периодов сверхрешетки), имеющими $N$-образную вольт-амперную характеристику, и перспективными умножительными гетеробарьерными диодами (варакторами) (рис. 1,b), имеющими вольт-фарадную характеристику $C(U)$ (рис. 2) параболического вида [1].

Гетеробарьерные варакторные диоды (ГБВ) являются одними из перспективных активных компонентов для создания эффективных умножителей частоты миллиметрового и субмиллиметрового диапазонов [7-9]. ГБВ реализуются на эпитаксиальных гетероструктурах, в которых полупроводниковый нелегированный материал с широкой запрещенной зоной, например InAlAs (барьер), „обложен“ с двух сторон легированным материалом с узкой запрещенной зоной InGaAs (модулирующий слой). Возможно чередование широкозонных и узкозонных материалов. Сопротивление таких диодов велико, что дает возможность подавать высокие напряжения при незначительных токах утечек. Барьеры в таких структурах не являются туннельно-прозрачными, а ямы - классические и используются для модулирования емкости слоя барьера [7]. Материал с широкой запрещенной зоной действует как потенциальный барьер для электронов и таким образом предотвращает сквозной транспорт электронов через структуру. Когда на устройство подается внешнее напряжение, электроны накапливаются на одной стороне барьера и наступает обеднение на другой стороне (рис. 3,a). Таким образом, устройство имеет зависящую от напряжения область обеднения в слое, прилегающем к барьеру, что определяет близкую к параболической форму вольт-фарадной характеристики (ВФХ) и определяет эффективность преобразования сигнала в 3-ю гармонику [7].

В исследуемых СР имеется периодическая система квантовых ям, разделенных узкими, туннельно-прозрачными потенциальными барьерами. В сверхрешетке формируется мини-зона. При подаче напряжения из-за взаимодействия движущихся носителей с потолком минизоны наблюдается $N$-образная ВАХ. 

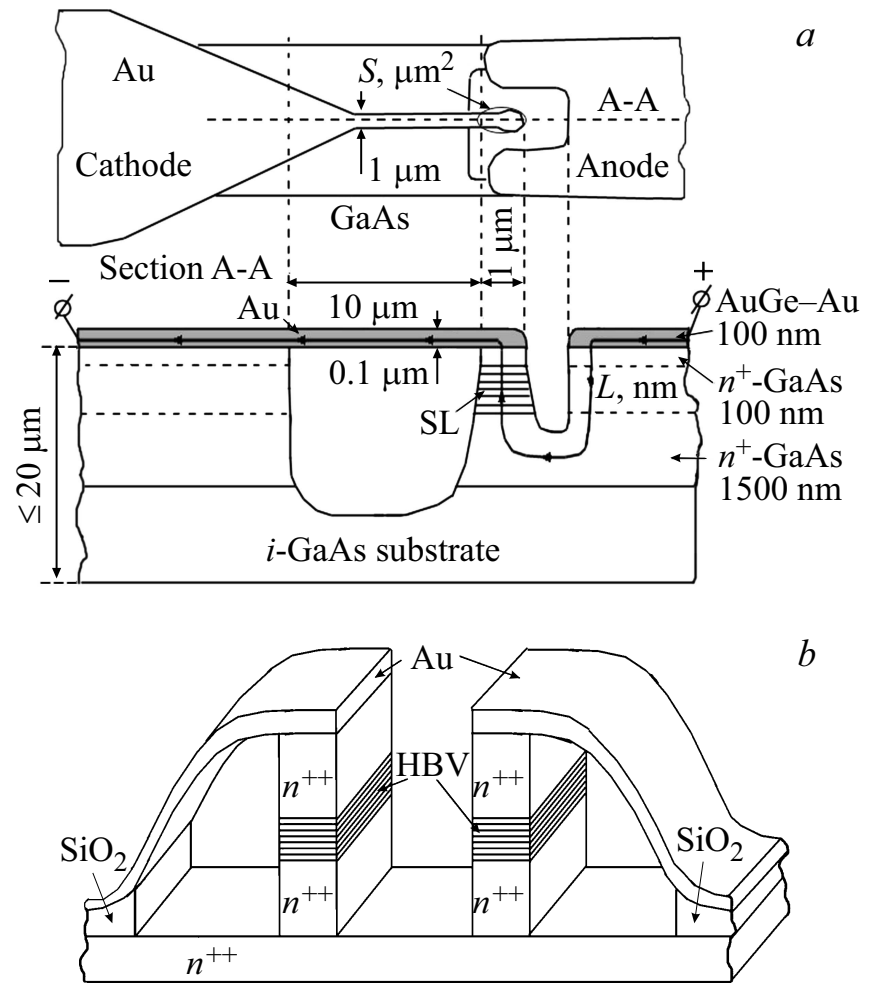

Рис. 1. Конструкция и эквивалентная схема исследуемых диодов. $a$ - диоды на основе $\mathrm{CP}, \mathrm{SL}-$ рабочая область диода со сверхрешеткой, стрелками показано направление тока в диоде, $S$ - площадь контакта $\left(1-20\right.$ мкм $\left.^{2}\right)$; структуры СР состояли из 18 периодов $(L=112$ нм), каждый период включал 18 монослоев GaAs и 4 монослоя AlAs. $b$ - гетеробарьерные диоды, HBV - гетеробарьерная структура варактора (ГБВ); конструктивно сборка ГБВ содержала 6 диодов (суммарная площадь $S=10^{2}-10^{4}$ мкм $^{2}$ ), соединенных с помощью металлических полосков, каждый содержал 4 барьера и 3 ямы.

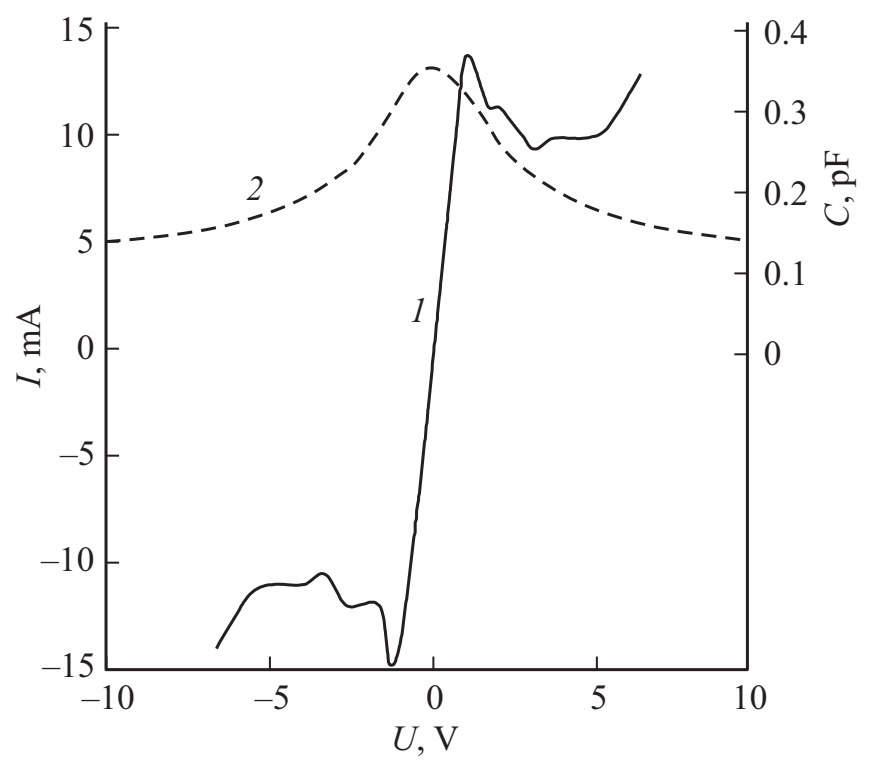

Рис. 2. Вольт-амперная характеристика (1) диода на основе $\mathrm{GaAs} / \mathrm{AlAs-cверхрешетки} \mathrm{и} \mathrm{измеренная} \mathrm{ВФХ} \mathrm{(2)} \mathrm{для} \mathrm{сборки}$ планарных структур ГБВ.
На рис. 3 представлены схемы зонных диаграмм исследуемых диодов. Различие диодов заключается в толщине барьеров, что приводит в случае диода на основе СР к нелинейной вольт-амперной характеристике $(\mathrm{BAX})$, а для гетеробарьерного варактора - нелинейной вольт-фарадной характеристике (ВФХ). В силу того что вид нелинейности указанных зависимостей различен, корректное сравнение возможно при сопоставлении параметров 3-й гармоники выходного сигнала. Обсуждение возникновения гармоник более высокой кратности будет привлекаться для обсуждения различий диодов.

Сравнение проводилось путем моделирования характеристик диодов с помощью разработанной ранее модели [5], а также на основе сопоставления экспериментальных данных. Проблема заключалась в том, что сопоставляемые диоды совершенно различны не только по конструкции, но и по принципам функционирования. Поэтому для корректного сравнения результатов, кроме обычного сопоставления выходной мощности и кпд, необходимо было рассматривать удельные (на 1 мкм² поперечной площади диода) мощности выходного сигнала.

\section{2. Результаты}

Конструктивно сборка гетеробарьерных варакторов содержала 6 последовательно соединенных диодов при поперечной площади, варьировавшейся в различных образцах в диапазоне $10^{2}-10^{4}$ мкм $^{2}$. Пары диодов соединялись с помощью металлических контактов, а внутри каждой пары соединение организовывалось за счет заглубленного проводящего $n^{+}$-слоя GaAs. Каждый из диодов содержал 4 барьера и 3 ямы (рис. 3, $b$ ).

Для сравнения были исследованы планарные диоды на основе сверхрешетки GaAs/AlAs с площадью активной области 1-20 мкм² (рис. 1,a). Структуры СР состояли из 18 периодов (1 период состоял из 1 ямы и 1 барьера), что соответствует длине 112 нм. Каждый период включал 18 монослоев GaAs и 4 монослоя AlAs (табл. 1, рис. $3, b)$.

На основе изготовленного варактора разработан умножитель частоты на 3 (табл. 2). Конструктивно умножитель представлял собой гетеробарьерный диод с переменной емкостью (ГБВ), включенный последовательно в микрополосковую линию (МПЛ), помещенную между двумя волноводами. Волноводы имеют сечения, соответствующие частотным диапазонам входного и выходного сигналов. Были выбраны следующие размеры сечения волноводов: $6.5 \times 2.8$ мм для входного сигнала частотой 31.3 ГГц и $2.4 \times 1.2$ мм для выходного сигнала частотой 94 ГГц. МПЛ изготавливается на подложке из поликора и содержит в себе элементы согласования, фильтрации и связи с волноводами. Корпус умножителя собирался из двух деталей. В корпусе вырезаны волноводные каналы и экранирующий канал для МПЛ. Входной и выходной волноводные каналы расположены ортогонально. Такое 
Таблица 1. Параметры исследуемых структур

\begin{tabular}{|c|c|c|c|c|}
\hline \multicolumn{2}{|c|}{$\begin{array}{l}\text { Исследуемые } \\
\text { структуры }\end{array}$} & $\begin{array}{c}\text { Толщина, } \\
\text { нм }\end{array}$ & $\begin{array}{c}\text { Уровень } \\
\text { легирования } N_{d}, \mathrm{~cm}^{-3}\end{array}$ & Особенности конструкции \\
\hline $\mathrm{CP}$ & $\begin{array}{l}\text { Яма }(b) \\
\text { Барьер }(a)\end{array}$ & $\begin{array}{l}5.08 \\
1.14\end{array}$ & $\begin{array}{l}10^{18} \\
10^{18}\end{array}$ & $\begin{array}{l}\text { Сверхрешетка, состоящая из } 18 \text { периодов, } \\
\text { каждый содержит } 18 \text { монослоев GaAs } \\
\text { и } 4 \text { монослоя AlAs (pис. } 3, b) \text {. }\end{array}$ \\
\hline ГБВ & $\begin{array}{l}\text { Яма }(b) \\
\text { Барьер }(a)\end{array}$ & $\begin{array}{c}13 \\
5\end{array}$ & $\begin{array}{c}3 \cdot 10^{17} \\
\text { Не легирован }\end{array}$ & $\begin{array}{l}\text { Сборка гетеробарьерных варакторов содержит } \\
6 \text { диодов, в каждом по } 4 \text { барьера и } 3 \text { ямы. } \\
\text { Диоды соединены за счет металлических } \\
\text { контактов (рис. } 3, a) \text {. }\end{array}$ \\
\hline
\end{tabular}

Примечание. Области контактов сильно легированы: для гетеробарьерной структуры $N_{d}=10^{19}$ см-3, для структуры на основе СР $N_{d}=2 \cdot 10^{18} \mathrm{~cm}^{-3}$.

Таблица 2. Достигнутые параметры умножителей на основе ГБВ и СР

\begin{tabular}{|c|c|c|c|c|c|}
\hline \multirow{3}{*}{ Параметр } & \multicolumn{3}{|c|}{ Эксперимент } & \multirow{2}{*}{\multicolumn{2}{|c|}{$\frac{\text { Расчет }}{\mathrm{CP}}$}} \\
\hline & \multirow{2}{*}{$\frac{\text { ГБВ }}{6 \text { диодов }}$} & \multirow{2}{*}{$\frac{\text { ГБВ [8] }}{2 \text { диода }}$} & \multirow{2}{*}{$\frac{\text { СР }}{1 \text { диод }}$} & & \\
\hline & & & & 1 диод & 6 диодов \\
\hline Частота входного сигнала, ГГц & 31.3 & 80 & 148 & 31.3 & 31.3 \\
\hline Частота выходного сигнала, ГГц & 94 & 240 & 444 & 94 & 94 \\
\hline Коэффициент умножения частоты & & & 3 & & \\
\hline Коэффициент полезного действия & 0.17 & 0.025 & 0.011 & 0.06 & 0.1 \\
\hline Выходная мощность, мВт & 111 & 2 & 0.1 & 5 & 30 \\
\hline Суммарная площадь диодов, мкм² & 6300 & 200 & 5 & 25 & 150 \\
\hline Удельная выходная мощность, мВт/мкм² & 0.017 & 0.01 & 0.02 & 0.2 & 0.2 \\
\hline
\end{tabular}

Примечание. Экспериментальные данные об умножителе на двух ГБВ диодах, в каждом из которых по два барьерных полупроводниковых слоя, взяты из [8].

расположение волноводов позволяет использовать подвижные короткозамыкатели для настройки умножителя. Также предусмотрена возможность перемещения МПЛ вдоль ее продольной оси, что позволяет менять положение варактора относительно волноводных каналов. Внутреннее устройство умножителя показано на рис. 4, $a$.

Планарные диоды на основе СР устанавливались в волноводную камеру $[6,10]$, которая имеет входной волновод сечением $2.54 \times 1.27$ мм и выходной волновод с частотой отсечки > 350 ГГц с диагональным рупором. Пример расположения планарного диода в волноводной камере показан на рис. 4, $b$ : планарный диод, расположенный в выходном волноводе, при проведении эксперимента возбуждался сигналом входной частоты $F$, равной 148 ГГц, и мощностью 15 мВт. Для согласования в широком диапазоне частот (140-160 ГГц) во входном волноводе расположен трансформатор сопротивлений, выполненный на гребенчатом волноводе (Fin-line) и согласующий поршень (backshort). В выходном волноводе установлен согласующий поршень на частоты 400-500 ГГц. Измерение спектра гармоник выходного сигнала проводилось при помощи фурьеспектрометра. Источником входного сигнала служил синтезатор частоты диапазона 118-178ГГц с пренебрежимо малыми интенсивностями собственных гар- моник, измерявшимися предварительно на этой же установке, их влияние на результаты измерений не учитывалось.

Экспериментальные данные (табл. 2) показывают, что кпд для утроителя на основе СР в $\sim 15$ раз ниже, чем для оригинального 6-диодного ГБВ, и в 2 раза ниже, чем для ГБВ на 2 диодах (данные взяты из [8]). В то же время удельная (на 1 мкм $^{2}$ поперечной площади диода) мощность выходного сигнала сравнима с удельной мощностью для 6-диодного ГБВ и в 2 раза выше, чем у 2-диодного. Экспериментально зарегистрированная мощность выходного сигнала умножителя на ГБВ на частоте 94 ГГц составляет > $100 \mathrm{мBт,} \mathrm{кпд} \mathrm{-} \mathrm{17 \% ,}$ что сопоставимо или даже выше параметров мировых аналогов.

Большая эффективность преобразования сигнала в утроителе на ГБВ объясняется тем, что параболическая зависимость емкости ГБВ от напряжения эффективно преобразует сигнал именно в 3-ю гармонику [7], тогда как преимущество диодов на СР заключается в большом наборе достаточно мощных гармоник более высокой кратности $[5,6]$. Сказанное позволяет рекомендовать диоды на основе СР для построения генераторов гармоник диапазона частот 0.1-1 ТГц, а ГБВ - для разработки утроителей частоты сигнала [7]. 
Был проведен расчет параметров умножителя на основе диодов на СР с входной частотой 31.3 ГГц (табл. 2). Для корректного сопоставления рассматривались один диод и сборка из 6 параллельно включенных диодов на основе СР с увеличенной площадью поперечного сечения. Результаты моделирования показали, что расчетная удельная выходная мощность для утроителя на основе СР (6 диодов) в $\sim 12$ раз больше по сравнению с экспериментальной для 6-диодного ГБВ, при этом кпд последнего больше в 1.7 раза.

Другим результатом расчета стало то, что при равных выходных мощностях сигналов, используя СР диоды меньшей площади (т. е. с меньшей рабочей и паразитной емкостями), можно получить выигрыш в эффективности преобразования на более высоких частотах исходного и умноженного сигналов.
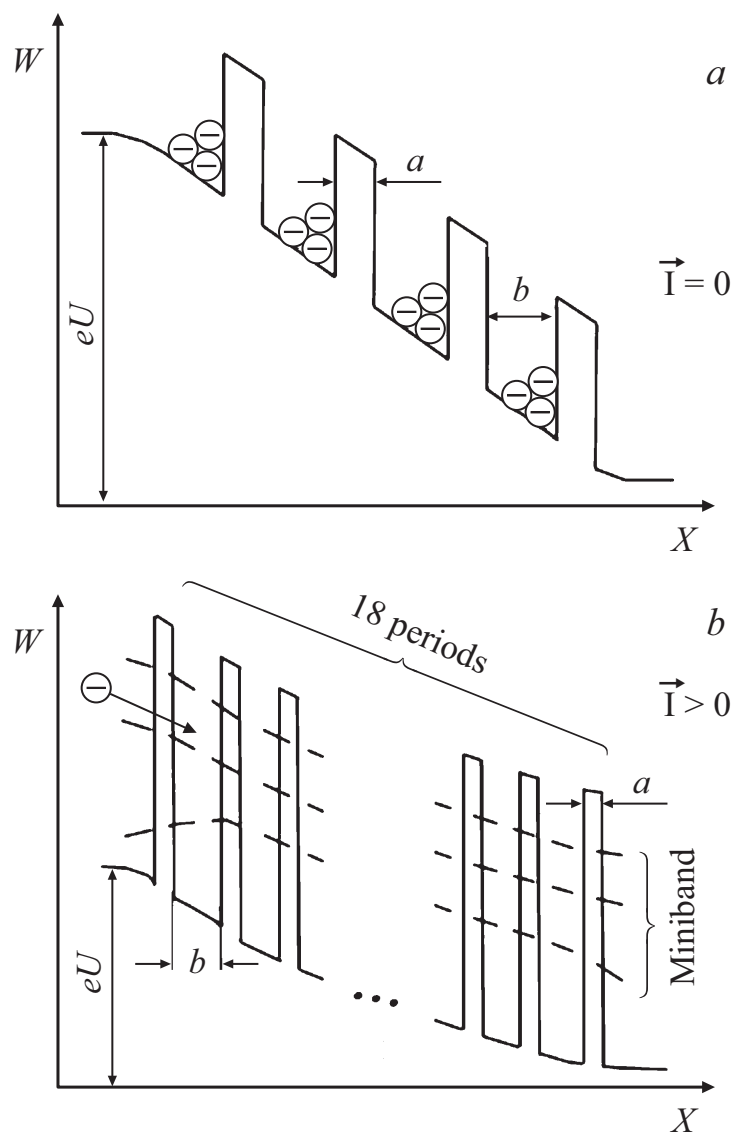

Pис. 3. $a-$ зонная диаграмма гетеробарьерной структуры, состоящей из 4 барьеров и 3 ям; барьеры не являются туннельнопрозрачными и ток утечки пренебрежимо мал $(I=0)$; в данном случае ямы - классические и используются для модулирования емкости слоя барьера, в этом участвуют и прилегающие слева и справа слои узкозонного материала; наблюдается ВФХ параболического вида для напряжения, равного нулю. $b-$ зонная диаграмма структуры $\mathrm{CP}$, состоящей из 18 туннельно-прозрачных барьеров и 17 квантовых ям, электроны пролетают через мини-зону (miniband), создавая ток диода $(I>0)$; параметры структур наблюдается $N$-образная BAX.

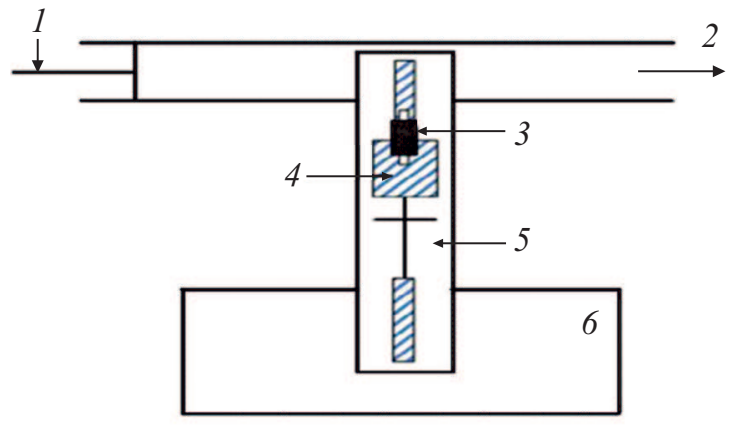

$a$

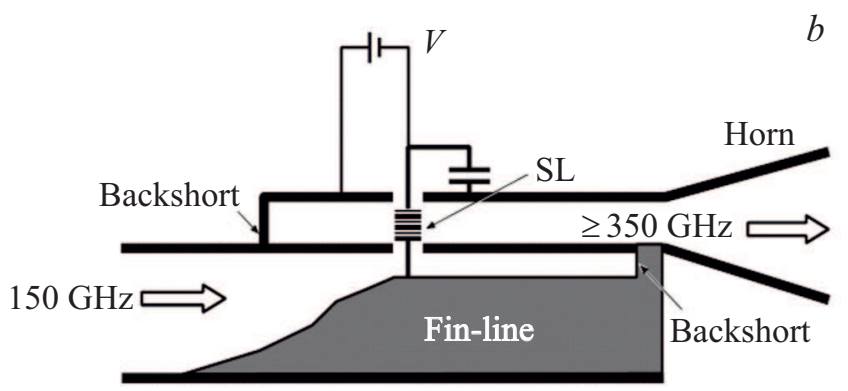

Рис. 4. $a-$ общий вид конструкции умножителя на основе ГБВ: 1 - подвижный короткозамыкатель; 2 - волновод $2.4 \times 1.2$ мм (выход); 3 - ГБВ-диод; 4 - микрополосковая линия (МПЛ); 5 - подложка $\mathrm{Al}_{2} \mathrm{O}_{3} ; 6$ - волновод $6.5 \times 2.8$ мм (вход). $b$ - пример расположения планарного диода на основе СР в волноводной камере $[6,10]$.

Важно понимать, что разница между конструкциями применяемых умножителей на ГБВ оригинальной конструкции заключается в использовании сапфировой подложки для крепления кристаллов ГБВ, которая является теплоотводом. Отказ от использования такой подложки при реализации СР ТГц преобразователей сигнала с высокой кратностью умножения приводит к ограничению предельных токов диодов из-за теплоотвода, который может быть осуществлен лишь через балочные контакты [11].

Как показано в данной работе, на частотах $<100$ ГГц возможна реализация параллельно-последовательного включения диодов на основе СР методами гибридного монтажа на диэлектрических пластинах, за счет чего теплоотвод может быть организован значительно лучше, а выходная мощность может быть повышена в 5-10 раз, так что будет достигать значений, сопоставимых с выходной мощностью утроителя на ГБВ. Оценки показывают, что на частотах $\sim 100$ ГГц возможно получение выходной мощности утроителя на диодной сборке до $30 \mathrm{MB}$.

\section{3. Заключение}

В результате проведенных экспериментов и расчетов показано, что кпд для утроителя на основе СР в $~ 15$ раз ниже, чем для ГБВ, при этом удельная (на 1 мкм $^{2}$ 
поперечной площади диода) мощность выходного сигнала может быть выше. Расчеты показали, что при использовании эффективного теплоотвода удельная выходная мощность для утроителя на основе СР (6 диодов) больше в $\sim 12$ раз по сравнению с экспериментальной для ГБВ, при этом их кпд может быть сравним. Это позволяет рекомендовать диоды на основе СР для реализации умножителей частоты на 3 и более в диапазоне частот > 100 ГГц, в то время как оригинальные сборки ГБВ диодов хорошо зарекомендовали себя в качестве утроителей в диапазоне выходных сигналов $\sim 94$ ГГц.

\section{Финансирование работы}

Работа поддержана грантом Министерства науки и высшего образования РФ, полученным в рамках ФЦП „Исследования и разработки по приоритетным направлениям развития научно-технологического комплекса России на 2014-2020 годы“. Уникальный идентификатор проекта RFMEFI62020X0003. Номер соглашения 075-15-2020-529.

\section{Конфликт интересов}

Авторы заявляют, что у них нет конфликта интересов.

\section{Список литературы}

[1] Е.С. Фефелова, Н.А. Малеев, В.А. Беляков. Сб. $т р$. ХІХ Координационного семинара по СВЧ электронике (2017) c. 79.

[2] С.М. Зи. Физика полупроводниковых приборов (М., Мир, 1985).

[3] М. Шур. Современные приборы на основе арсенида галлия (М., Мир, 1991).

[4] C.P. Endres, F. Lewen, T.F. Giesen, S. Schlemmer, D.G. Paveliev, Y.I. Koschurinov, V.M. Ustinov, A.E. Zhucov. Rev. Sci. Instrum., 78, 043106 (2007).

[5] Д.Г. Павельев, А.С. Иванов, В.А. Козлов, А.П. Васильев, Е.С. Оболенская. ФТП, 53 (9), 1218 (2019).

[6] Д.Г. Павельев, Ю.И. Кошуринов, А.С. Иванов, А.Н. Панин, В.Л. Вакс, В.И. Гавриленко, А.В. Антонов, В.М. Устинов, А.Е. Жуков. ФТП, 46 (1), 125 (2012).

[7] M. Ingvarson. Thesis for the degree of Doctor of Philosophy (Gothenburg, Chalmers University of Technology, 2004). http://publications.lib.chalmers.se/records/fulltext/4312.pdf

[8] J.R. Jones, S.H. Jones, W.L. Bishop, R. Lipsey. 7th Int. Symp. Space Terahertz Technology (Charlottesville, USA, 1996) p. 125.

[9] D. Choudhury, M.A. Frerking, P.D. Batelaan. IEEE Trans. Microwave Theory and Techniques, 41 (4), 595 (1993).

[10] D.G. Pavelyev, A.P. Vasilev, V.A. Kozlov, E.S. Obolenskaya, S.V. Obolensky, V.M. Ustinov. IEEE Trans. Terahertz Sci. Technol., 8 (2), 231 (2018).

[11] Д.Г. Павельев, А.П. Васильев, В.А. Козлов, Е.С. Оболенская. ФТП, 52 (11), 1337 (2018).

Редактор Л.В. Шаронова

\section{Comparison of the efficiency of promising heterostructural multiplier diodes of the $\mathrm{THz}$ frequency range}

\author{
D.I. Dyukov ${ }^{1}$, A.G. Fefelov ${ }^{1}$, A.V. Korotkov ${ }^{1,3}$,
} D.G. Pavelyev ${ }^{3}$, V.A. Kozlov ${ }^{2,3}$, E.S. Obolenskaya ${ }^{3}$, A.S. Ivanov ${ }^{1,3}$, S.V. Obolensky ${ }^{3}$

${ }^{1}$ Scientific-Production Enterprise Salyut JSC, 603950 Nizhny Novgorod, Russia

${ }^{2}$ Institute for Physics of Microstructures, Russian Academy of Sciences, 603087 Nizhny Novgorod, Russia ${ }^{3}$ Lobachevsky State University of Nizhny Novgorod, 603950 Nizhny Novgorod, Russia

Abstract In this paper, the results of a theoretical and experimental comparison of the signal conversion efficiency for diodes based on superlattices with a small number of periods $(N$-shaped current-voltage characteristic), with promising multi-plying heterobarrier diodes (varactors) (capacitance-voltage characteristic of a parabolic type) are presented. 